\title{
A cross sectional study on knowledge, attitude, practice regarding emergency contraception
}

\author{
Jahnavi Putchakayala*, Manjula Rao, Prashanthy Edwards, Mini Mohan
}

Department of Obstetrics and Gynecology, Durgabai Deshmukh Hospital and Research Centre, Vidya Nagar, Hyderabad, Andhra Pradesh, India

Received: 21 April 2018

Accepted: 23 May 2018

\section{*Correspondence:}

Dr. Jahnavi Putchakayala, E-mail: jahnavipu@gmail.com

Copyright: () the author(s), publisher and licensee Medip Academy. This is an open-access article distributed under the terms of the Creative Commons Attribution Non-Commercial License, which permits unrestricted non-commercial use, distribution, and reproduction in any medium, provided the original work is properly cited.

\section{ABSTRACT}

Background: Emergency contraception (EC) is the contraception administered to a woman after unprotected intercourse. This study aims to assess the knowledge, attitude, practice of emergency contraception among patients of 15-45 years attending Obstetrics and Gynaecology outpatient department.

Methods: A cross sectional study was conducted in Durgabai Deshmukh Hospital, Hyderabad during June 2014 to June 2016. This study included 300 women. A pre structured questionnaire was employed after obtaining informed written valid consent from the patient and institutional ethical committee clearance. Data on age, socio economic status, education, religion, marital status, their knowledge, attitude, practice regarding emergency contraception was obtained, tabulated and analysed using chi-square test.

Results: Out of 300 women, $52 \%$ belong to $15-25$ years, $31 \%$ belong to $26-35$ years, $17 \%$ belong to $36-45$ years. $21.6 \%$ of the study population heard of EC. Among these $51 \%$ heard from media, $24 \%$ from friends, $25 \%$ from medical personnel. $18.6 \%$ of the study population knew the correct time frame of use, knew that is not an abortion pill, effective in preventing pregnancy, could not prevent the spread of sexually transmitted diseases. $85 \%$ of the study population have positive attitude. $14.6 \%$ of the population practiced EC. Out of them $88 \%$ have used emergency contraceptive pills, $12 \%$ have used Intra uterine contraceptive device. $77 \%$ got EC over the counter, $23 \%$ got through prescription.

Conclusions: The study highlights the need to motivate women for effective and appropriate use of emergency contraception when required and arrest the trend towards unwanted pregnancy.

Keywords: Attitude, Emergency contraception, Knowledge, Practice

\section{INTRODUCTION}

Unintended pregnancy poses a major challenge to the reproductive health of young adults in developing countries.

With decreasing age of menarche and onset of sexual activity, young people are exposed early to unplanned and unprotected sexual intercourse leading to unwanted pregnancy and invariably abortions and its related morbidity and mortality. ${ }^{1-3}$ Emergency contraception
(EC) is the contraception administered to a woman after unprotected intercourse. Other indications include failure of barrier methods like the slipping or breakage of condoms and after rape. Thus EC may be an effective way to reduce the number of unwanted pregnancies and induced abortions.

Hormonal EC concept was introduced in India in 2000 made legal in 2003 and available over the counter from pharmacists since 2005 are a safe female controlled method of contraception. ${ }^{4,5}$ In spite of the legal 
availability of EC in India, empirical data on their acceptability and use are scant. Data from the 2005-2006 Indian National Family Health Survey indicate that $11 \%$ and $20 \%$ of women and men respectively, had heard of EC. ${ }^{6}$

WHO estimated that 84 million unwanted pregnancies occur annually worldwide. The WHO estimated nearly $21,600,000$ unsafe abortions took place in 2008, almost all in developing countries with restrictive abortion laws. ${ }^{7}$

Each year, about 210 million women around the world become pregnant from which about 75 million of these pregnancies (36\%) are unplanned or unwanted. ${ }^{8}$ Unplanned or unwanted pregnancy is one of the leading causes of maternal mortality and morbidity in developing countries. 9

In the developing countries, WHO estimates that one woman dies every eight minutes due to unsafe abortion. ${ }^{10}$

The aim of this study is to know the knowledge, attitude and practice of emergency contraception among women of 15-45 years attending obstetrics and gynaecology outpatient department in Durgabai Deshmukh Hospital and Research Centre, Hyderabad.

\section{METHODS}

This cross sectional observational study was conducted in department of obstetrics and gynaecology in Durgabai Deshmukh hospital and research centre, Hyderabad and included patients of 15-45 years attending obstetrics and gynaecology OPD in Durgabai Deshmukh hospital and research centre from June 2014 to June 2016, satisfying inclusion and exclusion criteria.The sample size was taken as 300 with confidence interval $95 \%$. Women of 15-45 years age group who were willing to participate in the study were included in the study.

After obtaining written informed consent, the questionnaire was administered for data collection on general information, knowledge, attitude, practice regarding emergency contraceptive practices. Primary variables were knowledge, attitude, and practice of study group regarding emergency contraception. Secondary variables were age, religion, region, education, SE status, marital status. Ethical committee clearance was obtained.

The collected data was analyzed with regard to the information given by the subjects according to the set questionnaire items and the analyzed data is presented in the following tables.

All the data was collected and subjected to statistical analysis in a systematic way. Qualitative data was analyzed by using Chi-square test and $\mathrm{p}$ value. $\mathrm{P}$ value less than 0.05 was considered statistically significant. The Statistical software SPSS version 19.0 was used for the analysis of the data and Microsoft word and Excel have been used to generate graphs, tables etc.

\section{RESULTS}

Most of the study population belong to age group 15-25 years $(52 \%)$, mean age of the respondents being 25 years (between 20 to 30 years). Majority of the study population belong to urban area $(88 \%)$. 65(21.6\%) heard of emergency contraception. $51 \%$ have heard of EC from media, $24 \%$ heard from friends, $25 \%$ heard from medical personnel (Table 1).

Table 1: Demographics of the study.

\begin{tabular}{|c|c|c|}
\hline Characteristic & $\begin{array}{l}\text { Number } \\
(n=300)\end{array}$ & Percentage \\
\hline \multicolumn{3}{|l|}{ Age (in years) } \\
\hline $15-25$ & 156 & 52 \\
\hline $26-35$ & 93 & 31 \\
\hline $36-45$ & 51 & 17 \\
\hline \multicolumn{3}{|l|}{ Marital status } \\
\hline Married & 219 & 73 \\
\hline Single & 81 & 27 \\
\hline \multicolumn{3}{|l|}{ Region } \\
\hline Urban & 264 & 88 \\
\hline Rural & 36 & 12 \\
\hline \multicolumn{3}{|l|}{ Religion } \\
\hline Hindus & 213 & 71 \\
\hline Muslims & 57 & 19 \\
\hline Christians & 27 & 9 \\
\hline Others & 3 & 1 \\
\hline \multicolumn{3}{|l|}{ Education } \\
\hline Illiterate & 54 & 18 \\
\hline Primary & 73 & 24.3 \\
\hline Secondary & 154 & 51.3 \\
\hline Higher & 19 & 6.3 \\
\hline \multicolumn{3}{|c|}{ Socioeconomic status } \\
\hline Low & 94 & 31.3 \\
\hline Middle & 175 & 58.3 \\
\hline High & 31 & 10.3 \\
\hline
\end{tabular}

$18.6 \%$ of the study population knew the correct time frame of use of EC, knew the drug is not an abortion pill, effective in preventing pregnancy, could not prevent the spread of sexually transmitted diseases. $85 \%$ of the study population have positive attitude towards EC. Many of the respondents supported the availability over the counter.

$14.6 \%$ of the population practiced EC. Out of them $88 \%$ have used Emergency contraceptive pills, $12 \%$ have used Intra uterine contraceptive device. $77 \%$ got $\mathrm{EC}$ over the counter, $23 \%$ got through prescription.

$26.9 \%$ of 15-25 years age group have correct knowledge of EC which is higher compared to other age groups. This difference was statistically significant ( $p$ value 0.00028 ). 
$21.1 \%$ of $15-25$ years are practicing EC which is higher compared to other age groups. This difference was statistically significant (p value 0.0027 ) (Table 2 and 4).

Table 2: Knowledge among various demographics.

\begin{tabular}{|lll|}
\hline A ge range & Yes $(\%)$ & No $(\%)$ \\
\hline $15-25$ & $42(26.9)$ & $114(73.1)$ \\
\hline $26-35$ & $12(12.9)$ & $81(87.1)$ \\
\hline $36-45$ & $2(3.9)$ & $49(96.1)$ \\
\hline Marital status & & \\
\hline Married & $46(21)$ & $173(78.9)$ \\
\hline Single & $10(12.3)$ & $71(87.6)$ \\
\hline Religion & & \\
\hline Hindus & $49(23)$ & $164(77)$ \\
\hline Muslims & $5(8.8)$ & $52(91.2)$ \\
\hline Christians & $2(7.4)$ & $25(92.6)$ \\
\hline Others & $0(0)$ & $3(100)$ \\
\hline Region & & \\
\hline Urban & $55(20.8)$ & $209(79.1)$ \\
\hline Rural & $1(2.8)$ & $35(97.2)$ \\
\hline Education & & \\
\hline Illiterate & $1(1.9)$ & $53(98.1)$ \\
\hline Primary & $4(5.5)$ & $69(94.5)$ \\
\hline Secondary & $44(28.6)$ & $110(71.4)$ \\
\hline Higher & $7(36.8)$ & $12(63.1)$ \\
\hline SE status & & \\
\hline Low & $4(4.2)$ & $90(95.7)$ \\
\hline Middle & $40(22.8)$ & $135(77.1)$ \\
\hline High & $12(38.7)$ & $19(61.2)$ \\
\hline
\end{tabular}

Table 3: Attitude towards emergency contraception.

\begin{tabular}{|lll|}
\hline Attitude & N & $\%$ \\
\hline Positive & 255 & 85 \\
\hline Negative & 45 & 15 \\
\hline
\end{tabular}

Knowledge and practice of EC is more among Hindus which is $23 \%$ and $18.3 \%$ respectively. This was higher compared to Muslims and Christians. This difference was statistically significant (p value 0.02 ) (Table 2 and 4 ).

Knowledge and practice of EC in urban population is $20.8 \%$ and $16.3 \%$ respectively. This was more compared to rural population. The difference was statistically significant (p value 0.009) (Table 2 and 4).

$36.8 \%$ have correct knowledge in higher education population, $28.6 \%$ in secondary education, $1.9 \%$ in illiterates. Awareness is more among educated population which was statistically significant (p value 0.00000041 ). Practice of EC is also more among educated population (Table 2 and 4).

$38.7 \%$ have correct knowledge in high class SE status population compared to $4.2 \%$ in low SE status. Awareness is more among high SE group which was statistically significant (p value 0.0000097). Practice of EC is more among high SE group (Table 2 and 4).

Table 4: Practice of EC among various demographics.

\begin{tabular}{|lll|}
\hline Age range & Yes $(\%)$ & No $(\%)$ \\
\hline $15-25$ & $33(21.1)$ & $123(78.8)$ \\
\hline $26-35$ & $9(9.6)$ & $84(90.3)$ \\
\hline $36-45$ & $2(3.9)$ & $49(96)$ \\
\hline Religion & & \\
\hline Hindus & $39(18.3)$ & $174(81.6)$ \\
\hline Muslims & $3(5.3)$ & $54(94.7)$ \\
\hline Christians & $2(7.4)$ & $25(92.5)$ \\
\hline Others & $0(0)$ & $3(100)$ \\
\hline Region & & \\
\hline Urban & $43(16.3)$ & $221(83.7)$ \\
\hline Rural & $1(2.8)$ & $35(97.2)$ \\
\hline Education & & \\
\hline Illiterate & $1(1.9)$ & $53(98.1)$ \\
\hline Primary & $3(4.1)$ & $70(95.8)$ \\
\hline Secondary & $34(22.1)$ & $120(77.9)$ \\
\hline Higher & $6(31.6)$ & $13(68.4)$ \\
\hline SE status & & \\
\hline Low & $3(3.1)$ & $91(96.8)$ \\
\hline Middle & $31(17.7)$ & $144(82.2)$ \\
\hline High & $10(32.2)$ & $21(67.7)$ \\
\hline Marital status & & $183(83.5)$ \\
\hline Married & $36(16.4)$ & $73(90.1)$ \\
\hline Single & $8(9.9)$ & \\
\hline
\end{tabular}

Knowledge and practice of EC among married population is $21 \%$ and $16.4 \%$ respectively. Among single population, it is $12.3 \%$ and $9.9 \%$ respectively. This difference was not statistically significant ( $p$ value 0.15 ) (Table 2 and 4).

\section{DISCUSSION}

Emergency contraception will definitely help to reduce unintended pregnancies as well as its consequences like induced abortions, complications which may arise during or after unsafe abortions. EC is also very useful option when there is failure of barrier methods. It is important for a woman to have correct knowledge about EC like when to use, its availability, correct dosage. Educated women can take the decisions regarding their family size, which family planning method to use, timing of pregnancy as the awareness regarding contraception is higher among educated women, more among higher socio economic status. Our objective was to know the knowledge attitude practice regarding emergency contraception

\section{Knowledge of EC}

Different studies have shown varying knowledge from 1$20 \%$. Knowledge in our study is $18.6 \%$ compared to 
other studies where knowledge was $13.4 \%$ in Ade et al and $20 \%$ in Murthy et al. ${ }^{11,12}$

Out of 300 population, 65 respondents $(21.6 \%)$ reported that they had heard about emergency contraception. Among those aware of EC, 51\% said they received their information from media, $25 \%$ heard about it from the medical personnel and $24 \%$ obtained it from their friends. While $18.6 \%$ believed that EC is effective in preventing pregnancy, $18 \%$ recognized that they could not prevent the spread of HIV. About $18 \%$ of respondents knew that the drug was not an abortion pill. Only $17 \%$ of the respondents knew the correct time frame for an effective use of EC to prevent pregnancy recognizing the need to take the first dose within 72 hours after having unprotected sexual intercourse.

\section{Attitude towards emergency contraception}

The attitude of the people regarding emergency contraception was favourable ( $85 \%$ positive). Many of the respondents supported the availability over the counter which is similar to Synchareun et al study. ${ }^{13}$

\section{Practice of EC}

Different studies have shown different statistics ranging from $1-20 \%$. In our study, practice of EC is $14.6 \%$ compared to study done by Lakkawar et al $(10.5 \%)$ and Singh et al (19.3\%). ${ }^{14,15}$

\section{CONCLUSION}

EC may have the potential to significantly reduce the morbidity and mortality associated with unsafe abortions which are a major cause of maternal deaths in developing countries. EC is also very useful option when there is failure of barrier methods. It is important for a woman to have correct knowledge about EC like when to use, its availability, correct dosage.

The level of knowledge and practice of EC among people in this study is very low. Regarding attitudes towards EC, the majority of respondents strongly supported the availability of EC in the public and private sectors. Very few people have actually heard of EC. Among them, only few have correct knowledge about the time frame of usage, dose and effectiveness.

\section{Recommendations}

- We need to adopt an aggressive promotional and educative approach to make more and more women of reproductive age group aware of EC.

- Efforts should be focused on providing health education regarding EC to youth and young adults both male and female, with focus on the available methods, correct timing of use, and the health effects of EC. It should use all major means of communications on EC such as peers, media as well as delivering messages through health facilities.

- The health executives should give due attention to design strategies and strengthening the health education in all health facilities as well as high schools and colleges focusing on the availability and options of Emergency contraceptives.

- OTC supply of ECP without prescription but with pharmacist counselling may increase reduction of unintended pregnancy and abortion. The provision of better quality service with client friendly approach will improve the acceptability of EC services.

- We should educate about high risk sexual behaviour.

- Providers working with women in clinics, emergency departments and pharmacies should be familiar with the availability of medications, as well as options for provision. Patient preference, provider capability, and local availability should influence which options are most preferable. Provision of better facilities could act as a motivating factor.

\section{Limitations of the study}

In spite of the efforts taken, there are limitations

- Due to the nature of the cross-sectional design.

- This was a relatively small survey conducted only in OPD of one hospital. Thus, there is a need to investigate in other settings within the country where health facilities may be more constrained.

- The study population is not representative of all young adults in the city and hence generalizing the results of this study to other settings must be done with caution.

- This study is limited to women although men comprise the decision making component in our country.

- Due to the sensitive nature of this study, the respondent's honesty and disclosure might be constrained. However, we tried to minimize this bias by building a good rapport by ensuring confidentiality and privacy.

\section{ACKNOWLEDGMENTS}

I realized that dissertation being a work of co-operation and assistance. It would be far from complete without due acknowledgement of the help gratefully received. I would like to begin thanking almighty for giving me this life and opportunity to serve humanity by this noble profession.

It is a great pleasure to express my thanks and profound sense of gratitude to my guide, Dr. Prashanthy Edwards, Senior consultant, Department of Obstetrics and Gynaecology, Durgabai Deshmukh Hospital and Research Centre, Andhra Mahila Sabha, Hyderabad for her inspiration, meticulous guidance, suggestions, expert advice and constant encouragement during the course of my study and preparation of this dissertation. 
My heartfelt thanks to all my consultants, Dr. Manjula Rao, Dr. Vijayalakshmi Kodati, Dr. Rekha, Dr. Mini Mohan, Dr. Kusumalatha and Dr. Shruthi M. for their valuable guidance and constant support I owe my gratitude to my friends Dr.Sushmitha, Dr Bhavani, Dr. Sirisha, Dr Ameena, Dr. Biji, Dr. Sushma, Dr.Padmavathi, and Dr. Dhawal, Dr Revathi, Dr Vasudha, Dr Madhusri, Dr Tejaswi without their help and support this dissertation would never have been complete.

I thank my parents, in laws, my brother and my cousins for their incredible love and support, for their constant help, encouragement and inspiration during the study and all my family members deserve a very special word of appreciation, I express my sincere thanks to them. I would like to express special thanks to my life partner Dr. Rami Reddy, without his help I would have never completed my work. Last but not the least, I am obliged to all my patients who provided me the opportunity to conduct this work. I thank all the patients and the hospital staff for their co-operation, without whom dissertation would have never been materialized.

Funding: No funding sources

Conflict of interest: None declared

Ethical approval: The study was approved by the Institutional Ethics Committee

\section{REFERENCES}

1. Dhillon BS, Chandhiok N, Kambo I, Saxena NC. Induced abortion and concurrent adoption of contraception in the rural areas of India (an ICMR task force study). Indian J Med Sci. 2004;58(11):478-84.

2. Kalter HD, Mohan P, Mishra A, Gaonkar N, Biswas $\mathrm{AB}$, Balakrishnan $\mathrm{S}$, et al. Maternal death inquiry and response in India-the impact of contextual factors on defining an optimal model to help meet critical maternal health policy objectives. Health Res Policy Sys. 2011;9(1):1.

3. WHO, UNICEF, UNFPA, The World Bank. Trends in maternal mortality: 1990 to 2008. http://whqlibdoc.who.int/publications/2010/9789241 500265_eng.pdf. Published 2010. Accessed 10 January 2018.

4. Family Planning Division, Ministry of Health and Family Welfare. Guidelines for Administration of Emergency Contraceptive Pills by Health Care Providers: November 2008. Available at
http://mohfw.nic.in/NRHM/FP/ECP_Book_Final.pd. Accessed 10 January 2018.

5. Trussell J, Raymond EG, Cleland K. Emergency contraception: a last chance to prevent unintended pregnancy. Contemp. Readings L Soc Just. 2014;6:7.

6. International Institute for Population Sciences (IIPS). India National Family Health Survey (NFHS-3), 2005-06. IIPS; 2007.

7. WHO. Unsafe abortion. Global and regional estimates of the incidence of unsafe abortion and associated mortality in 2008. Sixth. Geneva, Switzerland; 2008.

8. WHO. Unsafe Abortion-Global and Regional Estimates of the Incidence of Unsafe Abortion and Associated Mortality. Geneva: WHO; 2004.

9. Adhikari R. Factors affecting awareness of emergency contraception among college students in Kathmandu, Nepal. BMC women's health. 2009;9(1):1.

10. El-Sabaa HA, Ibrahim AF, Hassan WA. Awareness and use of emergency contraception among women of childbearing age at the family health care centers in Alexandria, Egypt. J Taibah Univ Med Sci. 2013;8(3):167-72.

11. Ade AD, Patil R. Contraceptive practices and awareness of emergency contraception among Muslim women of urban slum of Raichur, Karnataka. Int J Reprod Contracept Obstet Gynecol. 2014;3(1):70-4.

12. Murthy MSR. Knowledge of Emergency contraception in the Southern states of India. Ethno Med. 2014;8(3):277-83.

13. Sychareun V, Hansana V, Phengsavanh A, Phongsavan K. Awareness and attitudes towards emergency contraceptive pills among young people in the entertainment places, Vientiane City, Lao PDR. BMC women's health. 2013;13(1):1.

14. Lakkawar NJ, Magon S, Alaganandam $P$. Assessment of attitude towards use of emergency contraceptives among antenatal women. Int J Reprod Contracept Obstet Gynecol. 2014;3(4):1067-72.

15. Singh V, Thakur P, Nayak PK, Agrawal S. KAP of emergency contraceptive pills among women of reproductive age group attending AIIMS OPD Raipur (CG). International J. 2014;1(2):105-12.

Cite this article as: Putchakayala J, Rao M, Edwards P, Mohan M. A cross sectional study on knowledge, attitude, practice regarding emergency contraception. Int J Reprod Contracept Obstet Gynecol 2018;7: 2869-73. 